\title{
An analysis of core-competences of successful multinational team leaders
}

\author{
Aida Hajro \\ Lecturer in International Business \\ Brunel University Business School \\ Uxbridge, Middlesex \\ UK - London - UB8 3PH \\ e-mail: aida.hajro@brunel.ac.uk \\ Tel: +44 (0) 1895267658 \\ Markus Pudelko \\ Professor of International Business \\ Tübingen University \\ Melanchthonstraße 30 \\ 72074 Tübingen \\ e-mail: markus.pudelko@uni-tuebingen.de
}

\section{Biographical notes:}

Aida Hajro is lecturer at Brunel University Business School. She holds a $\mathrm{PhD}$ degree from the Vienna University of Economics and Business Administration (WU), where she has previously worked as assistant professor at the Research Institute for European Affairs. Her research focuses on multinational teams, organisational culture, team learning, knowledge transfer and cross-border mergers and acquisitions. Her most recent book publications include: Numic, A. (2008) Multinational Teams in European and American Companies, Peter Lang Publishing Group, Frankfurt, Germany.

Markus Pudelko is Professor of International Business at Tübingen University and worked previously for the University of Edinburgh Business School. He has earned Masters degrees in Business Studies (University of Cologne), Economics (Sorbonne University) and International Management (Community of European Management Schools - CEMS) and a $\mathrm{PhD}$ (University of Cologne). His current research is on headquarters-subsidiary relationships, comparative HRM, Japanese management, multinational teams, the impact of language on international business and cross-cultural management. He has published on these topics in books, book articles and journals such as Human Resource Management, Long Range Planning, Organizational Dynamics and International Journal of Human Resource Management. 


\title{
An analysis of core-competences of successful multinational team leaders
}

\begin{abstract}
:
Researchers have endeavoured to understand the factors that enable effective functioning of multinational teams (MNTs) but with few exceptions they have ignored studying the competences of MNT leaders. In this paper we present those competences leaders must possess in order to effectively lead MNTs. Our findings are based on 70 problem-centred interviews with MNT leaders and members from five multinational corporations. The competences our interviewees mentioned most frequently for effective leadership were knowledge management and transfer. Results further indicated that a leader must be crossculturally competent and multilingual in order to motivate MNT members to fully explore, exploit and transfer valuable knowledge within the team and beyond.
\end{abstract}

Keywords: multinational teams, leadership, competences, knowledge management, crosscultural competence, motivation, language, corporate culture 


\section{Introduction}

Despite the fact that a substantial body of literature is addressing the performance of teams in general, MNTs still remain a relatively understudied field of research. Multinational teams are defined here as organisational teams consisting of three or more individuals from two or more different countries who are provided with tools and procedures to address certain sets of organisational tasks over a longer period of time (Earley and Gibson, 2002). Several authors have argued that MNTs can provide advantages for organisations (Earley and Gibson, 2002; Earley and Mosakowski, 2000; Ely and Thomas, 2001), while others have described more negative processes that occur in MNTs (e.g., Shapiro et al., 2002; Watson et al., 1998). Researchers have endeavoured to understand the factors that enable the effective functioning of MNTs, but only few team performance models have specified leadership as a central driver of team processes (e.g. Zaccaro et al., 2001; Fink et al., 2004a). More specifically, with few exceptions (e.g., Joshi and Lazarova, 2005), researchers have ignored studying the competences of MNT leaders.

In order to fill this gap in the literature, the purpose of this study is to explore the competences that leaders should possess in order to effectively lead MNTs. This study has been conducted across five companies and is based on 70 problem-centred interviews with 38 MNT leaders and 32 MNT members. The participants have been asked to explain how a team leader can improve the effectiveness of his/her team and cope with critical incidents that are likely to emerge in MNTs. The problem-centred interviews were analysed by qualitative content analysis using Atlas.ti software. Several team leader competences that contribute to team success have been identified. 
In the following, we provide a review of the current research related to leadership in MNTs. Subsequently, the method of data collection and analysis is outlined in detail, followed by the presentation and the discussion of our results.

\section{Leadership in MNTs}

Given the increasing complexity of work and the growing workforce diversity, MNTs have been introduced to many organisations (Earley and Gibson, 2002). With the success of Japanese manufacturers, Western organisations sought to identify keys to team success and strove to imitate these features in their own organisations. As a consequence, teamwork has been frequently adopted also in Western companies (Erez and Earley, 1993; Butler and Earley, 2001). Globalisation has increased pressure on these teams, requiring them not only to perform to high standards, but also to do so across geographically dispersed business units. This trend suggests that an increased understanding of how to make best use of MNTs contributes to competitive advantage (Butler and Earley, 2001).

Literature on MNTs is characterised by several inconsistencies. Some studies show, for example, that MNTs are more innovative and derive higher quality solutions (Ely and Thomas, 2001; Earley and Mosakowski, 2000; O’Reilly and Chatman, 1996; Cox et al. 1991); others find that international diversity is detrimental to performance in the long run, showing that homogeneous teams are more innovative and better performing (Watson et al., 1998; Watson et al., 1993).

Research specifically focussed on leadership in MNTs is with few exceptions (e.g., Joshi and Lazarova, 2005) still conceptual, anecdotal, or based only on single-country samples (Kirkman et al., 2004), indicating that it is still in a very early stage of development. 
Joshi and Lazarova (2005) conducted a phone-interview based study with 89 MNT members and 50 MNT leaders from a Fortune 500 company. They identified four competences for effective leadership that were considered to be important by respondents across multiple locations: communication; direction and goal setting; motivating and inspiring; and facilitating teamwork. In particular communication and goal setting were perceived by a clear majority (65\% or more) of the MNT members in each country as significant MNT leader competences; these two competences thus seem to be generally viewed as key to successful MNT leadership. Given the universal appeal of the four above cited competences among the respondents, for this study it was proposed that these might be viewed as "core competences" of effective MNT leadership. Surprisingly, none of these competences is specific to leadership in a cross-cultural context as they all also apply to mono-cultural teams.

According to Zaccaro et al. (2001) MNT leaders are primarily responsible for defining team goals, setting the direction, organising the team work and supporting the team to accomplish its mission. Fink et al. (2004a) argue that they also play an important role in the implementation phase of any team work. During this interaction process of MNTs, the experienced team leader influences the perceptions and expectations of team members and stresses shared objectives and mutual interests. Experienced managers, who know which norms proved successful in previous teams, can contribute to the performance of current teams by influencing the development of their norms. Successful MNT leaders also do so by the selection of people and the delegation and implementation of tasks.

Maznevski and DiStefano (2000) suggest that MNT leaders need to be able to map, bridge, and integrate the different perspectives of MNT members. In a similar vein, Matveev and Nelson (2004) explored the relationship between cross cultural communication competence and MNT performance. Their goal was to find out if a high degree of cross-cultural 
communication competence of team members affects the performance of MNTs. Crosscultural communication competence entails a general knowledge of the relevant cultures and languages, affective and behavioural skills such as empathy, human warmth, charisma, and the ability to manage anxiety and uncertainty. More specifically, they distinguish in their work between different dimensions of cross cultural communication competence. Regarding the interpersonal skills dimension, a team member of high cross cultural communication competence acknowledges differences in the communicative and interactional styles of people from different cultures and feels comfortable when communicating with them. The team effectiveness dimension includes such critical skills as the ability of a team member to understand team goals and norms and to pass them on to other members of an MNT. The cultural uncertainty dimension reflects the ability of a team member to be patient in intercultural situations, to be tolerant and accept cultural differences, and to work in a flexible manner with others in an MNT. Finally, according to the cultural empathy dimension, a culturally empathetic team member behaves as though he or she understands the world as do team members from other cultures, shows an appreciation for a variety of working styles, and an ability to view the ways things are done in other cultures not in a negative way but simply as different. The results of Matveev and Nelson's study (ibid) show that there is a positive relationship between the level of cross-cultural communication competence of MNT members and the performance of their MNT. More specifically, and for our study more importantly, the two authors claim that in particular leaders of MNTs must be good cross-cultural communicators in order for a team to perform well.

Schwer (2004) argues that team leaders with international experience should possess a higher degree of cultural awareness and empathy which should help them reframe conflicts and misunderstandings, change wrong perceptions of others in the team, break stereotypes and 
establish commonly shared and accepted team norms. Such individuals are likely to contribute to the overall success of diverse teams.

Cummings (2007) studied 129 teams working across different units in a multinational company. Results suggest that a good communication style of team leaders versus their team members mitigates the negative impact of high geographical dispersion. He concluded that leaders should communicate with team members who are dispersed across different units of a multinational company more frequently than they typically do and that they should create for such teams norms that encourage team members to communicate among themselves frequently and openly.

Although cross-cultural research emphasises that different cultural groups have different conceptions of what leadership should entail, a recent study has shown that attributes associated with charismatic and transformational leadership are universally endorsed as contributing to outstanding leadership. This hypothesis was confirmed as part of the GLOBE Research Program (Dickson et al., 2006) across 60 nations. Consequently, charismatic and transformational leaders are able to create and handle effective teams and be helpful in transferring and implementing successfully applied team norms.

Also according to Schweiger et al. (2003) MNT leadership is critical. Many of the successful MNT leaders are able to succeed because of their ability to manage the complexities of MNT functioning and navigate the team context. The authors identified a number of the personal capabilities and characteristics relevant to increased performance. These are the ability to understand skills needed on an MNT; to have a solid relationship with subsidiaries; to be multilingual; to have project management skills; to have a high need for achievement; and to demonstrate open-mindedness for learning. 
A review of the relevant literature, which we have briefly summarised above, indicates that research has so far been limited to investigating primarily individual characteristics of team leaders. If context has been considered, it was the immediate context of the leaders' own teams. What researchers have so far ignored, however, is studying the role of MNT leaders within their overall organisational context and, in addition to that, across different organisations simultaneously. What we understand from current research is that MNTs need successful team leaders, who are capable of exploiting the team's full potential. But is there a set of specific leadership requirements across all companies or do leadership requirements differ in different institutional settings? In other words, does the organisational context impact MNT leaders' performance? And how can organisations identify and develop team leaders? And ultimately, what does really make a MNT leader successful? These are important, essential and timely questions. Their answers will assist companies in increasing team leader performance in their specific organisational context.

The purpose of our study is to find answers to these important questions. In contrast to previous studies on MNT leadership we investigate MNT dynamics and the role of leaders within the overall organisational context. The fact that this study has been conducted in-depth in five different organisational settings allows us to compare the results across companies and to obtain a much closer understanding of the relevance of the organisational context within which MNT leaders are operating.

\section{Method}

\section{Data collection and sampling}

In order to cover both the role of MNT leaders and the institutional context within which they operate we rely on multiple sources of evidence. Non-standardised interviews, based on 
problem-centred, narrative questions are the primary data source of this study. This type of interview is open, i.e. the interviewer has to stimulate a conversation. The problem-centred interview is a theory-generating method that is designed to overcome the tension of the researcher being either already preconditioned by theory (and thus risking a blindness to unforeseen results) or being fully undirected by any theoretical concepts (and thus not being able to ask the relevant questions). It is through the iterative interplay of inductive and deductive probing and reflection around critical incidents that the researcher generates new knowledge (Witzel, 2000). In the narrative interview the interviewed person is encouraged to openly and freely talk about his/her experiences, enabling the collection of subjective opinions of the interviewee (Mayring, 2000). Consequently, new, surprising and pervasive cognitions can be gathered, which might be less likely to achieve in the framework of a systematic standardised questioning.

70 problem-centred interviews with narrative questions have been conducted with 38 MNT leaders and 32 MNT members from five companies: one Austrian electronics company (here: $A E$ ); one regional HQ of a German chemical company (here: $G C$ ) based in Austria; one US American consumer goods company (here: $A C G$ ); one German electrical engineering company (here: GEE); and one Finnish engineering services firm (here: $F E S$ ). The main criteria for the selection of case companies were the multinationality of their workforces and the diversity of approaches toward MNTs, allowing for a wide spectrum of results.

Data collection has been aimed at developing new conceptual categories up to the point of theoretical saturation. It emerged that a situation where no new categories or properties resulted from the gathering of additional data has been attained after conducting six to seven interviews with team members or team leaders per informant company. However, in all five cases we have conducted additional interviews in order to ensure that the point of theoretical 
saturation has been attained. Respondents came from a variety of nationalities. Table 1 provides more details about the interviewees. Interviews were conducted in 2005 and 2006 and lasted, on average, for one hour. All interviews have been taped and a transcript has been produced. The interviews have been conducted in German, English or Bosnian.

- Insert Table 1 about here -

By asking predominantly 'what', 'how' and 'why' questions, we could obtain a rich picture of what has been occurring in the five case organisations. Interviews were conducted with individual team members and leaders sharing common experiences of working together in the same companies. Team members and team leaders were encouraged to tell their own stories and experiences. Thus we collected workplace stories about critical incidents and remarkable issues in teams; which challenges team leaders face in their teams; how they manage their teams; what they expect from team members and what team members expect from them; and finally about which competences successful team leaders possess. This information allowed for a rich picture to emerge which reflects the reality and complexity of organisational and team life.

Valuable information has also been obtained through actual participation in the organisations and extensive observations of MNT leaders' interactions with team members. Participant observations were conducted by the first author and a research assistant. By spending time in the companies the investigators could gain a deeper understanding for the dynamics of the social settings, MNT processes and MNT functioning. The context has been deliberately part of the design and research issues have been examined by setting them in a contextual and causal relationship. 


\section{Data analysis}

Textual analysis of the interviews has been undertaken with ATLAS.ti computer software support. By enabling the researcher to document the method, ATLAS.ti makes the collection and analysis of data as comprehensible and transparent as possible. The researcher is aware of every single step in the analysis model which helps increasing the validity of the measurement. Two coders were involved in data analysis and both worked with ATLAS.ti. Inter-coder reliability was reached by coding the same sample of twelve interviews from two informant companies (GEE, FES) first independently from each other and subsequently by reanalysing the same data together, discussing the results and reaching an inter-coder agreement on the codes and categories derived from the analysis. Coding rules were refined until the assessment suggested an adequate level of agreement.

We used the content analysis method (Mayring, 2000) to analyse the interviews. Inductive category development and deductive category application are the two central approaches of this method of data analysis. The goal is to develop the categories that are as close as possible to the underlying data and to formulate them in a way that reflects best the content of the gathered material. In order to avoid the risk of being overwhelmed by the sheer volume of unstructured data, first inductive categories have been formulated; in a second step, main categories and sub-categories based on the theoretically derived aspects of analysis have been deduced.

Finally, the constant comparative method has been applied. In an iterative process, data obtained in each company has been conceptualised separately into an individual, companyspecific framework and the resulting categories were compared across the different organisations. 


\section{Competences of MNT leaders}

According to the interviewees, effective team leadership turned out to be one of the most important factors enabling the effective functioning of MNTs. We have identified several competences that were considered as important by both, MNT leaders and members. In Table 2 we present a summary of our findings, indicating the number of quotations per MNT leadership competence mentioned by interview partners and the percentage of interview partners who stressed the importance of the various competences.

- Insert Table 2 about here -

Our interviews revealed that by far the most frequently mentioned team leader competence (47\% of interviewees; 77 quotations) is knowledge management and transfer, as MNT leaders contribute to the creation and dissemination of knowledge within an MNT and beyond. 20\% of the interviewees mentioned the following competences as essential for MNT leaders: cross-cultural awareness (30 quotations); motivation (25 quotations); and social competence (23 quotations). MNT leaders need to be cross-culturally competent in order to decrease the number of critical incidents in their culturally diverse teams, be able to motivate members to contribute to common team goals, and have general social skills in order to run a team. According to the interviewees goal setting (16\% of interviewees; 13 quotations) and decisionmaking (14\%of interviewees; 12 quotations) are also important roles of an MNT leader. Leaders are expected to define, communicate and facilitate the acceptance of MNTs' goals by helping team members understand how their mission contributes to the overall business strategy. $11 \%$ of the interviewees mentioned the following core competences of MNT leaders: the ability to select the right team members (18 quotations); to delegate the right tasks (15 quotations); constructive monitoring (13 quotations); knowledge of foreign languages (110 quotations) and work experience (9 quotations). Team leaders need to make sure that the right 
people are on the team, know who should take over which task and observe the progress team members are making and direct them accordingly, in order to enhance the overall team performance. Furthermore, as communication is essential for managing an MNT a shared language is indispensable. Multilingual team leaders facilitate and interpret conversations when necessary and improve the knowledge transfer processes in an MNT. In addition, a leader should have an in-depth experience of working in the company and a deep knowledge of company objectives, procedures, and the organisational culture. The experienced team leader assists new team members and inpatriates who are on rotational assignments at HQ to understand the corporate values and behavioural norms. As for the inpatriates, once they return to their home country, they can pass these values and norms on to their local colleagues. Thus, an MNT leader facilitates the transfer of $H Q$ 's organisational culture, a competence that was raised by $10 \%$ of the interviewees ( 7 quotations). Also coordination (10\% of interviewees; 14 quotations) has been identified as an important MNT leader competence, as project managers spend most of their time coordinating the activities of their sub-teams. Other MNT leader competences that were raised by our respondents were coaching (7\% of interviewees; 10 quotations); conflict management (7\% of interviewees; 8 quotations); creation of collective team identification (6\% of interviewees; 7 quotations); recognising strengths and weaknesses of MNT members (7\% of interviewees; 6 quotations); ability to show humility (6\% of interviewees; 5 quotations); self-awareness (3\% of interviewees; 4 quotations); and finally the ability to provide virtual team-leadership (3\% of interviewees; 2 quotations).

Due to the limited scope in this paper, we will provide more in-depth information on five competences that are generally viewed as key competences of MNT leaders and that are considered by the interviewees to be tightly interrelated: knowledge management and transfer, cross-cultural awareness, motivation, knowledge of foreign languages and the 
ability to facilitate the transfer of the organisational culture of $H Q$ to host-country subsidiaries.

\section{Knowledge management and transfer: the facilitating MNT leader}

Our data indicated that by far the most frequently mentioned competence for an MNT leader (47\% of interviewees; 77 quotations) is knowledge transfer and management. MNTs play a central role in the knowledge creation process of multinational companies. In all of our five case companies, it became evident that MNT leaders play an important role in facilitating the interaction between team members and in resolving potential conflicts caused by cultural differences. They help team members to integrate and make sense of new perspectives.

At $G C$ the principle behind creating its system of knowledge exploitation and knowledge transfer is job rotation. MNTs consist to $80 \%$ of rotating team members from different subsidiaries and from the HQ. Employees work together in MNTs over a sufficiently long period of time (one to two years) to consolidate close relationships. Knowledge-sharing activities in MNTs lead to the exploitation of very useful knowledge that contributes to the successful implantation of strategic and marketing activities in local subsidiaries. Discussions lead to the creation of new knowledge and this knowledge enables the company to stay ahead of the global competition and gain competitive advantage. Teams consisting of HQ employees and inpatriates who work at the regional Austrian HQ also facilitate the exploitation and transfer of knowledge across geographic and organisational boundaries of the company. Inpatriates develop a contextual understanding of the practices employed at the regional HQ. Once they return to their home country, they are able to transfer this knowledge to their local subsidiaries. At the same time, employees at the regional HQ learn about different strategies of conducting business in the host-countries. Expatriates from the regional HQ are also sent to the local subsidiaries to share their knowledge and gain a deeper understanding of the 
business operations in the region. This approach is fully consistent with company's desire to encourage all its teams worldwide to contribute a multicultural perspective to its global strategy development, enabling the company to act as globally as possible, yet as locally as necessary.

Interviews indicate that through rotational assignments $G C$ is developing cross-culturally competent MNT leaders who are capable of facilitating the interactions between team members from different countries. The experienced team leader influences members' perceptions and promotes shared objectives. It is the team leader who creates a positive team climate. He/she increases the willingness of inpatriates to share their knowledge in MNTs at the regional HQ. Inpatriates thus transfer local knowledge of competitors and local consumers, whilst influencing new product development, branding and advertising. After the assignment in Austria they would successfully transfer the local and the newly created knowledge to a different business unit.

"...it is very important that they (host country representatives) are here, that we share our knowledge and that they transfer this knowledge from Austria to their subsidiaries at the end of their rotational assignment. This exchange of valuable, context-specific information is very important since otherwise we would talk about something that we do not really understand (GC: Austrian team leader, female).”

$A C G$ actively pursues knowledge exploration and knowledge exploitation in its product development through intensive interactions between team members from different teams, departments and subsidiaries. The task of the team leaders is to facilitate this purposeful knowledge creation by encouraging the knowledge exchanges between employees, by providing a sense of direction, by facilitating the communication between team members and 
by stressing the advantages of these interactions. MNT leaders serve as a bridge between the ideas of employees from different departments and subsidiaries. They link different activities and businesses into one whole:
"We have sales people, we have marketing people in there, we have product development people in there and every major division in the company is represented. .... After exhaustive discussions we come up with new ideas and future plans.... Mr. P. provides a sense of direction and he encourages the interactions between members who work together in teams (ACG: American team leader, male)."

At $A C G$ HQ in the US $70 \%$ of MNT members are Americans and $30 \%$ foreigners. In the initial stages, cultural diversity has more negative consequences for the teams, since team members are more likely to experience poorer communication and decision-making and greater conflict which, in turn, result in lower levels of team performance. Under these circumstances, the experienced team leader is responsible for developing clear rules of interaction. He must stress similarities and explain cultural differences between team members in order to form trust and develop cohesion. This is very important in order to facilitate the knowledge creation process since cultural diversity among team members may create barriers to effective group interaction. Cultural characteristics may divide the network into subgroups and stop the formation of interpersonal relations leading to the creation of nationally homogeneous subgroups consisting of either American or foreign members. The cross-culturally competent MNT leaders at $A C G$ facilitate the interaction between team members and the knowledge transfer between different departments of the company.

At GEE, MNTs have a certain type of structure that facilitates the interactions and knowledge management within these subunits of the organisation. They are organised in a so-called team leader system. Two types of MNT leaders operate in the company. The external team leader is 
responsible for the communication with external parties, e.g. customers, subcontractors, suppliers. His/her main responsibility is to communicate with these parties and exchange important information. The internal team leader is responsible for the internal coordination of an MNT team. The external team leader reports to the internal team leader. He/she provides a sense of direction while the internal team leader serves as a bridge between the two parties and plays a key role in the knowledge creation process. The internal team leader synthesises the knowledge, makes it explicit and communicates it to the external leader and the team members. Team members are familiar with the details of products and markets but they find it challenging to communicate this information to the external leader. In order to share knowledge, it is important that all parties involved perceive and interpret the context in more or less the same way (Nonaka and Takeuchi, 1995). Due to different communication patterns, knowledge may lose its meaning when communicated to the external leader. Moreover, it often happens that team members are not fluent in English, so that the language barrier creates additional challenges and uncertainty. This uncertainty, in turn, leads to anxiety and avoidance of interaction. The internal team leader, therefore, acts as the knowledge broker. $\mathrm{He} / \mathrm{she}$ is able to access MNT knowledge that is hidden from the view of the external team leader. The information about MNT activities and achievements is tied into bundles and then transferred by the internal team leader to the external team leader.

“...... we made big progress with introduction of the team leader system. External team leaders are responsible for external communication and the internal team leader communicates with individual developers. When you have around 40 developers in one team and everybody tries to discuss something with somebody else then the whole process becomes rather uncoordinated and unsystematic. But with this team leadership structure the communication is coordinated. The internal team leader has direct access to ideas, knowledge and different perspectives of team members. He communicates this information to the external leader (GEE: Austrian team leader, male)." 
Furthermore, the implementation of a team leader system also facilitates cross-cultural communication in a virtual context. External MNT leaders are responsible for transferring team knowledge across geographic boundaries.

Knowledge management and knowledge transfer have also been identified as core competences of MNT leaders at FES. The team structure at FES is very similar to GEE's MNT structure. The external team leader is responsible for the communication with external parties while the internal team leader's responsibility is to coordinate members' interactions and to transfer the knowledge from the external team leader to MNT members and vice versa. MNTs at FES are composed of representatives from different countries who are interdependent in terms of tasks and goals and are mutually accountable to each other to accomplish those goals. Team members may also come from different companies. This represents additional challenges for team leaders in terms of identity formation and collective team identification. The internal team leader communicates with the external team leader who may be a representative of a different company and, as a member of a different organisation, he/she is likely to hold different work values and a different understanding of corporate culture, policies, procedures and best practice systems. Internal team leaders have to turn information they receive from the external leader into useful knowledge. Their task is to communicate the importance of this knowledge to MNT members which puts them at the centre of knowledge management. They must communicate the knowledge to team members so that it does not lose its meaning in a different context. Furthermore, the knowledge created in MNTs must be made explicit by internal team leaders inside the existing team and then transferred to external team leaders. The following quotation illustrates the experience of an MNT leader at FES: 
"For me there are two different areas of collaboration: [...] there is the project team in Salzburg, where I am the internal team leader, I have to lead a small group of people. Then, I have to coordinate things also with the external project leader. [...] And the other team is the team in Sofia. But I do not have to build up a tight relationship with this team. It is organized in a similar way as our team. There is also one external project leader (in this case I am the external leader), and an internal team leader with whom I communicate. I don't communicate with the team members in Sofia (FES: Austrian team leader, male).,

Knowledge management and transfer are also considered to be a crucial MNT leader competence at $A E$. In order to facilitate the sharing and application of knowledge in the team, successful project managers create norms that encourage team members to communicate among themselves. Under these circumstances team members become motivated to share valuable knowledge:
"Knowledge management.... I know that I mentioned its relevance before. It is important to make sure that people don't only pass text or data on but share information and work together. The team leader has to make sure that the environment is fitting to support a real communication (AE: American team leader, male)."

The results from all five informant companies demonstrate how MNT leaders facilitate the creation and transfer of knowledge within MNTs and across geographically dispersed business units of the company. The core process of creating organisational knowledge takes place at the team level (see also Nonaka and Takeuchi, 1995). MNT leaders are at the very centre of knowledge management. We consider this as an important finding since prior research has mainly focused on expatriate knowledge transfer and learning. With few exceptions (Baba et al., 2004) the role of the MNT leader in the process of knowledge creation has been neglected. 


\section{Cross-cultural awareness: the interculturally competent MNT leader}

Our interviews revealed, furthermore, that cross-cultural awareness (mentioned by $20 \%$ of interviewees; 30 quotations) is, after knowledge management capabilities, the second most important competence for MNT leaders. In fact, the inability of MNT leaders to simultaneously work with people from many cultures was cited as one of the major causes of MNT failure. Consequently, MNT leaders should know about the values and beliefs of people from various cultures and be willing to adapt their own behaviour to different contexts. Only by displaying sensitivity in cross-cultural interactions they can build social relations with their team members.

The GC example shows how MNT leaders are developed through cross-cultural assignments. These assignments have been described by our interviewees at $G C$ as significantly contributing to improved MNT performance and success. Employees gain factual and conceptual knowledge about management in different countries through cross-cultural training sessions. Before starting the rotational assignment they are familiarised with the political, economic and social system of the foreign country and gain an understanding of the value system and how it affects behavioural patterns. Already when recruiting employees, $G C$ is looking for candidates with some international experience, who are open-minded, tolerant, flexible and willing to face new challenges. Cross-cultural assignments and the frequent exposure to other cultures through the establishment of MNTs facilitate the transfer of attributional knowledge. Attributional knowledge is a type of tacit knowledge that is informal, personal, and difficult to communicate in a classroom based training system (Johnson et al., 2006). The transfer of this knowledge takes place through socialisation in MNTs. In order to systematically develop cross-culturally competent MNT leaders, strong institutional support is of essence. At $G C$ corporate norms of behavior are transferred through expatriates and returning inpatriates to host country subsidiaries. Thus, expatriate and inpatriate team 
members are involved in the creation of a unified corporate culture. This also implies that corporate values are not enforced on MNT leaders or members. The socialisation in MNTs, cross-cultural assignments and the corporate culture of $G C$ all facilitate the acquisition of soft skills, including tacit knowledge, and the development of cross-culturally competent MNT leaders as is illustrated by the following quotation:

"A team leader must be aware of cultural differences. He must be interested in foreign cultures and motivated to learn from other team members. We develop future leaders through numerous rotational assignments and in MNTs... (GC: Austrian team leader, male). “

For the success of $A C G$ it is critical that MNT members develop solid relationships with a variety of people from different countries. Consequently, they must be cross-culturally competent and have the required interpersonal abilities. It is necessary that they are able to change their behaviour in order to cope with the environment. By adopting their behaviour, MNT leaders help decrease communication problems, uncertainty, misunderstandings and inefficiency in MNTs. This process enables them to work successfully with people from different countries.

"Here, you have to provide leadership. Whether it is formulating clear goals, whether it is resolving conflicts, whether it is making good decisions, whether it is providing resources, or whether it is sometimes solving problems. ...People look at you as a team leader and you have to provide some kind of leadership. Being a team leader here (in the USA) is much more difficult than in India. You have to honour that every single day. .... We all actually adjusted and learnt their system (ACG: Indian team leader, male)."

At GEE interviews revealed that MNT leaders face additional challenges. The company is strongly influenced by the socio-cultural context of the home country (Germany). It has a 
strong, explicit corporate culture based on HQ values that form the organisational cultures of its foreign subsidiaries. This sometimes has a negative impact on MNT leaders' ability to respond appropriately to cultural differences. By imposing the HQ ways of working on MNT leaders, organisations limit their ability to work effectively with other national groups and at the same time decrease MNT leaders' ability and willingness to acquire new, attributional and context specific knowledge about different cultures. Leaders in such companies are usually rewarded for their ability to do things the company way:

“...it is good if you have your own culture in your country but in the company we would like you to respect [GEE] 's corporate culture. And this is something we also expect team leaders to consider when leading teams. They are expected to do it the company way.... (GCC: Austrian team leader, male)”

The findings demonstrate that cross-cultural competence is one of the core competences of MNT leaders. A cross-culturally competent MNT leader is therefore (1) interested in foreign cultures; (2) aware of cultural differences; (3) posses cultural empathy; and (4) is motivated to learn from MNT members about their culturally determined norms and values of behaviour. Based on our data, we support Earley's (2002) point of view that cultural knowledge and awareness are necessary but not sufficient for performing effectively in a cross-cultural setting. An MNT leader must also have the motivation to use the available knowledge. Our study also shows that while intercultural competence can be taught to some degree, in order to develop cross-culturally highly competent MNT leaders companies must provide institutional support in more than one way. This is in accordance with the literature (see, for example Johnson et al., 2006). 


\section{Motivation: the inspiring MNT leader}

Another strong area of agreement among MNT leaders and MNT members regards the importance of motivating capabilities (20\% of interviewees; 25 quotations) as one of MNT leader's core competence. To motivate MNT members from different countries, functions and divisions of the company is a very challenging task. An organisation must be able to quickly mobilise employees with diverse capabilities into well functioning teams to respond to new challenges and contribute to the company's success. Project teams are by definition timelimited and team members come from different disciplines and organisational units. In an organisational set-up based purely on functional hierarchical authority lines, team members all have different superiors. Consequently, the team leader who has no line management authority is usually limited in his control over his team members by motivating them to work for a common goal. In order to keep his team members motivated, interested and committed, he has to focus more on the personal level.

"Again it comes down to how you motivate these people to do the work. ... Most project managers in this company do not have hierarchical authority and therefore not the priority; they can operate only with a more consensus-based control over the people. You have to keep this personal level very strong, to keep the commitment, to keep the interest, to keep the dedication...because you cannot tell them: 'I am the boss and do what I say. When I say jump, then jump.' Because they do not work for you. Within a corporate hierarchy, they actually have a different boss (AE: American team leader, male)."

In addition, the task of the team leader is to motivate members to explore and exchange their different opinions and perspectives. Motivation increases team members' openness to new knowledge and willingness to share important information. In order to facilitate the sharing and application of knowledge in the team, MNT leaders have to create norms that encourage team members to communicate among themselves more frequently (Fink et al., 2004a; 
Cumming, 2007). Under these circumstances team members identify more with their team and become emotionally attached. Leaders contribute to strong team identification by increasing the contact among team members through informal events, regular meetings or outdoor activities. Yet, the same group or individual rewards are not motivating across cultures. Motivational efficacy of rewards for team members from different countries will differ. Our results show, for example, that team members from Central and Eastern European countries stress more safety and social needs compared to Western European team members and that employees from India are compared to Americans more motivated by recognition and autonomy than by pay. The MNT leader should be aware of these differences.

Motivation and inspiration have also been identified as important MNT leader competences by Joshi and Lazarova (2005) and by Schweiger et al. (2003). This starts with members' shared sense of identification with a group. A team leader helps create collective team identification (Van Der Vegt and Bunderson, 2005). He/she increases the level of trust and cooperation within the group and motivates members to accept and offer useful knowledge and promote the free flow of information.

\section{Knowledge of foreign languages: the multilingual team leader}

Knowledge of foreign languages (11\% of interviewees) is another important factor.

Communication is essential to management of MNTs. Yet communication relies upon a shared language. MNT members are not always fluent in the corporate language. The linguistic diversity creates language barriers and language barriers create significant obstacles to do business, find new solutions, transfer valuable knowledge, build trust, promote a common team identity and increase team effectiveness (Harzing and Feely, 2008). Language differences may cause even greater problems than cultural differences in MNTs (Schweiger et al., 2003). Communication in a foreign language increases the complexity of communication 
processes within MNTs, leading to the emergence of critical incidents. It makes it more difficult to diffuse company information as is described in the following quotation:

"Working with ... HQ, one of the biggest barriers and challenges, is just the language barrier and certainly that has implications for me and for M. .... Somebody is translating for us. You know, I am spelling out this part of information and somebody needs to translate this to her and I have no idea what it is that is being communicated to her. And I just hope that they grab and pass on the entire essence of what I am saying and not just kind of filtering what they consider the most important part. ... We depend on the trust of the translators ... I am the leader of the team in Vienna and everything would be much easier if I could speak German (ACG: American team leader)."

In addition, language as a marker of group identity creates barriers to effective group interaction and leads to subgroup formation. It is the responsibility of multilingual team leaders to bridge this gap between team members. The linguistic diversity in MNTs increases the degree of uncertainty in interactions and harms the information flow. In order to increase the level of trust and interactions of members from different groups, it is important that the team leader is multilingual. The knowledge of different languages helps him/her to maintain communication richness in MNTs and prevent subgroup formation.

The process of creating organisational knowledge takes place at the team level. Knowledge is created by team members and internal team leaders are at the centre of knowledge management. The internal team leader synthesises the knowledge created in MNTs, makes it explicit and communicates it to the external leader. Without a common language, cooperation between MNT leaders is impossible. The internal team leader is involved in the process of socialisation where the sharing of experiences between team members and the creation of tacit knowledge take place. He must facilitate this interaction and prevent any communication breakdowns. In a next step, he should transform tacit knowledge into explicit concepts and 
then introduce and explain these concepts to the external team leader. Consequently, they must use a common language if they are to transfer knowledge, discuss problems, and create new solutions.

In accordance with our findings Schweiger et al. (2003) stress the fact that multilingual leaders have many advantages. They can interpret and facilitate conversations when necessary. According to Gudykunst (1995) the degree of uncertainty in interpersonal interaction will be inversely correlated with language competence. This uncertainty will lead to a lack of trust and to increased anxiety. Members will avoid interaction with members who do not speak their language. Consequently, language barriers will play a key role in multilingual group relationships (e.g., MNTs at $A C G$ ). We agree with Harzing and Feely (2008) that more research on the impact of language on international management is required. In order to avoid sub-group identity formation, improve communication between HQ and subsidiaries and increase the level of knowledge exploration and exploitation, MNTs need multilingual team leaders.

\section{Transfer of HQ's organisational culture: the MNT leader as a stimulator of shared} values

Another area of agreement among MNT members and leaders regards the importance of creating a system of shared values and norms in MNTs, thus facilitating the transfer of $H Q$ 's organisational culture. Interviews indicate that by employing inpatriates in MNTs on semipermanent rotational assignments, $G C$ creates a strong corporate culture characterised by common values and business methods throughout the entire company network. Newly formed MNTs may not start with a high level of agreement on important work related values. MNT leaders are responsible in this situation for defining team norms that regulate communication and decision-making procedures in their teams. They help team members understand what is 
important and how to behave in the organisation. Team members are encouraged to express their point of views and are actively involved in the process of creating a system of shared values and norms of behaviour. It is very important that the corporate culture is not imposed on culturally diverse employees. Team norms should allow members to adjust. Their fundamental cultural values must not diverge from corporate values. Inpatriates who are on rotational assignment at HQ become familiar with its corporate culture. Once they return to their home country they are able to work more effectively within the strategic direction and culture of the organisation and transfer aspects of the HQ culture to the local business units. This way they facilitate the creation of a shared company mindset which supports the willingness of the employees to share knowledge among the host country subsidiaries and HQ. MNT leaders are responsible for providing guidance to new team members and enhancing their ability to work within HQ strategic directions. For this, team leaders need to have a deep knowledge of company objectives, procedures and organisational culture. Host country representatives are frequently future MNT leaders, consequently this assignment is not limited to HQ representatives or expatriates sent by HQ to other locations.

The $G C$ example demonstrates that a prerequisite for global efficiency, local responsiveness, and worldwide learning is a multidirectional flow of knowledge between all global units. This is achieved through the frequent rotation of individuals and the promotion of a shared organisational culture (Bartlell and Ghoshal, 1989). Global mobility, diversity of experiences and common values allow for the transfer of tacit knowledge across geographic boundaries (Bonache and Brewster, 2001). MNT leaders, as HQ representatives, expatriates or even inpatriates, help to develop, promote and spread common values between different business units. This contributes to an increased motivational disposition to accept and offer useful knowledge, thus promoting the free flow of information (Gupta and Govindarajan, 2000). Individuals are the prime movers of knowledge creation within an organisation (Nonaka and 
Takeuchi, 1995). Yet knowledge is to a significant extent created on the group level, specifically in MNTs, and team leaders frequently stand at the forefront of knowledge creation within their teams and the knowledge dispersion among different teams. Similarly, the value creation and diffusion processes frequently take place on the group level; and again MNT leaders are at the very centre of this process. This aspect has been neglected so far in the literature and is an important contribution of this study.

\section{Discussion}

As previously described, several authors have argued that MNTs can provide strategic advantages for organisations (e.g., Earley and Gibson, 2002), while others have cited negative processes that occur in MNTs (e.g., Shapiro et al., 2002; Watson et al., 1998). Only a few team performance models have specified leadership as a central driver of team processes (e.g. Zaccaro et al., 2001). Our study makes an important contribution to the existing literature by directing the attention to the relevance of effective team leadership and by identifying key competences of successful MNT leaders across different organisational settings.

The interviews reveal that by far the most important role of an MNT leader is knowledge management and transfer. MNT leaders play a key role in the knowledge creation process and act as a communication interface between team members and external parties. Team members develop new ideas that are context specific. Communicated to the external parties these ideas may lose their meaning in a different context. The experienced MNT leader synthesises this knowledge, makes it explicit and communicates it to external parties. Despite the fact that learning in teams is seen as a key mechanism through which learning organisations become strategically and operationally adaptive and responsive (Edmondson et al., 2007), only little attention has so far been given to knowledge creation and sharing in MNTs (Zellmer-Bruhn and Gibson, 2006; Edmondson et al., 2007). As prior studies have also ignored the role of 
MNT leaders in the knowledge creation process, we argue that our findings present an important further contribution to MNT literature.

Moreover, our data show that, if managed appropriately, MNTs consisting of HQ employees, expatriates and inpatriates can be very effective in transferring knowledge across geographic and organisational boundaries. We argue that knowledge exploration and exploitation take place to a substantial degree at the team level and that MNTs represent a key mechanism for fostering cross-boundary knowledge generation and transfer. We have highlighted the importance of MNT leaders in this process and also stressed the relevance of the organisational context. MNT leaders have a deep knowledge of company objectives, procedures and the organisational culture.

Furthermore, in order to be able to integrate the different and frequently divergent perspectives of culturally dissimilar team members, our data show that MNT leaders require cross-cultural awareness. Past research has tried to measure the antecedents of cross-cultural competence rather than determining how the acquisition of cross-cultural skills can be facilitated (Johnson et al., 2006). Our interviews reveal that cross-culturally competent MNT leaders are developed in particular through rotational assignments and the socialisation in MNTs which also facilitate the transfer of attributional knowledge.

We have further shown that the generation, sharing and transfer of knowledge require that MNT members and MNT leaders interpret key contextual stimuli in similar ways. In order to discuss problems, create new solutions and transfer knowledge, they need to share a common language. However, little is known so far about the impact of language on MNTs. According to our interviewees MNT leaders should have knowledge of foreign languages in order to prevent communication breakdowns and contribute to team success. Understanding how 
language impacts the role of MNT leaders is among the most interesting issues for future research.

In contrast to previous studies on MNT leadership we have investigated the role of leaders within the overall organisational context. The fact that this study has been conducted in-depth in five different organisational settings has allowed us to compare the results across companies and to obtain a much clearer understanding of the relevance of the institutional context. Our findings reveal that MNT leaders must have a strong institutional support in order to facilitate the generation and transfer of tacit knowledge. In companies with a strong, ethnocentric HQ corporate culture leaders are mainly rewarded for their ability to assure that processes are followed in the company's way. However, by imposing the HQ's way on MNTs, the company limits its ability of working effectively with other national groups and decreases team members' motivation to acquire new, attributional knowledge. Consequently, we argue that an ethnocentric HQ-based organisational culture has a negative impact on MNT leaders' ability to respond appropriately to cultural differences, whereas a more inclusive corporate culture facilitates the acquisition of soft skills, encompassing the generation and transfer of knowledge. Most previous studies on MNTs have been conducted in laboratory settings or through short visits to companies during which questionnaires were distributed to convenience samples (Numic, 2008; Hajro, 2009). However, our study revealed that the context of an organisation shapes to a considerable degree MNT leaders' behavior and that it is difficult to understand their role without an explicit consideration of the institutional context. We consider this finding to be another important contribution to the MNT literature. 


\section{Conclusions, implications and future research}

In order to identify and develop competent MNT leaders we believe that companies should be guided by the following six recommendations: First, companies should be aware of the competences that MNT leaders should possess to effectively lead such teams. These are among others: knowledge management and transfer; cross-cultural awareness; motivation; goal setting; decision-making; selection of team members; delegation of tasks; monitoring; knowledge of foreign languages; coordination; and transfer of HQ corporate culture. Second, companies should value the role of the MNT leader, in particular in the knowledge creation process. He/she has to prevent any communication breakdown in MNTs and is responsible for converting context-specific into context-generic knowledge. Third, companies have to provide a strong institutional support for MNT leaders by creating a corporate culture that is compatible with the basic conceptions of all parties involved. Only a shared and commonly accepted corporate culture will motivate members to share knowledge. An ethnocentric corporate culture that rewards MNT leaders for their ability to do things only the HQ's way will reduce their ability to respond appropriately to cultural differences. Fourth, companies should develop MNT leaders through numerous cross-cultural assignments and the socialisation in various MNTs, first as team members and subsequently as team leaders. Through foreign assignments MNT leaders access context-specific knowledge and learn to understand different cultures, perspectives and interests of host-country subsidiaries. The learning experience in MNTs enhances their cross-cultural competence and provides them with new international perspectives. Fifth, companies should be aware that during the early stages of a team formation MNTs are likely to experience a low degree of internal agreement, as cultural differences increase the level of complexity in MNTs. The experienced team leader who has a deep knowledge of company objectives, procedures and the organisational culture will enable host country representatives to overcome these problems and work more effectively within this context. Sixth, companies should only select cross-culturally competent 
and ideally also multilingual MNT leaders who will be able to motivate members to share and transfer valuable knowledge within the team. This is especially true if they are positioned at the intersection between their team members and external parties. Knowledge transfer requires that MNT leaders interpret key contextual stimuli in a similar way to the knowledge generators and then transform this knowledge so that it is fully understood by external parties. The use of a common language is essential in this context.

In future, we should continue studying the competences of MNT leaders. A more systematic investigation of this phenomenon is needed and requires that MNTs in multiple organisations, located in multiple cultural contexts and operating in different industries are included in the sample. Interviews should be conducted by researchers with different national backgrounds in order to avoid construct and interview bias. Our findings will need to be followed up and specified through more empirical research. Many of our interview partners were Austrians. In order to explore if there are specific MNT leadership requirements to certain cultures, MNT leaders and MNT members from more countries should be included in future research samples. Moreover, leaders may be perceived differently in different industries and different institutional contexts. By identifying competences of MNT leaders and looking into differences of leadership styles in different organisations, it will be possible to improve MNT performance. More attention should also be devoted to the links between team leadership and the organisational and cultural context in order to identify the factors that influence MNT leadership success. Exploring these factors further presents an interesting avenue for future research. 


\section{Acknowledgement}

We would like to acknowledge the excellent research assistance of Alexandra Rubesch from the Vienna University of Economics and Business Administration. 


\section{References}

Baba, M.L., Gluesing, J., Ratner, H. and Wagner, K.H. (2004) The contexts of knowing: natural history of a globally distributed team. Journal of Organisational Behaviour, 25(5), $547-87$.

Bartlett, C. and Ghoshal, S. (1989) Managing across borders: The transnational solution. Harvard Business School Press, Cambridge.

Bonache, J. and Brewster, C. (2001) Knowledge transfer and the management of expatriation. Thunderbird International Business Review, 43(1), 145-168.

Butler, C.L., and Earley, P.C. (2001) Multinational Groups and the Structuration of Organizational Culture: a Sociological Perspective; in Cooper, C.L., Cartwright, S., Earley, P.C. (Eds.), Organizational Culture and Climate, 53-85. John Wiley \& Sons Ltd, New York.

Cox T., Lobel S., and McLeod P. (1991) Effects of ethnic group cultural differences on cooperative and competitive behaviour on a group task. Academy of Management Journal, 34 (4), 827-847.

Cummings, J.N. (2007) Leading group from a distance: How to mitigate consequences of geographic dispersion. In: S. Weisband and L. Atwater (Eds.), Leadership at a distance: research in technologically supported work, Lawrence Erlbaum Associates, Mahwah, NJ.

Dickson, M.W., Den Hartog, D.D. and Mitchelson, J.K. (2006) Research on leadership in a cross-cultural context: Making progress, and raising new questions. Leadership Quarterly, 14(6), 729-768.

Earley, P.C. (2002) Redefining interactions across cultures and organizations: moving forward with cultural intelligence. In B.M. Staw and R.M. Kramer (Eds.) Research in Organisational Behaviour, 24, 271-299, Elsevier, Oxford.

Earley, P.C., and Gibson, C.B. (2002) Multinational Work Teams: A New Perspective. Lawrence Erlbaum Associates, Mahwah, NJ.

Earley, P.C. and Mosakowski, E.M. (2000) Creating hybrid team cultures: An empirical test of international team functioning. Academy of Management Journal, 43(1), 26-49. 
Edmondson, A.C., Dillon, J.R and Roloff, K.S. (2007) Three Perspectives on Team Learning

Outcome Improvement, Task Mastery, and Group Process. Academy of Management Annals, $1(1), 269-314$.

Ely, R. D. and Thomas, D. A. (2001) Cultural diversity at work: The effects of diversity perspectives on work group processes and outcomes. Administrative Science Quarterly, 46(2), 229-273.

Erez, M. and Earley, P.C. (1993) Culture, self-identity and work. Oxford University Press, New York.

Fink, G., Neyer, A. K., Kölling, M. and Meierewert, S. (2004a) An Integrative Model of Multinational Team Performance. EI Working Paper Nr. 60, WU Wien.

Fink, G., Neyer, A. K., Kölling, M. and Meierewert, S. (2004b) Research on intercultural management interaction: the cultural standard method. Paper presented at the First International Co-Sponsored Conference, Research Methods Division Academy of Management, in Lyon, France.

Gibson, C.B., Zellmer-Bruhn, M.E., and Schwab, D.P. (2003) Team Effectiveness in multinational organizations: evaluation across contexts. Group and Organization Management, 28(4), 444-474.

Gudykunst, W.B. (1995) Anxiety/uncertainty management (AUM) theory: Current status. In R.L. Wiseman (Eds.), Intercultural communication theory, 8-58, Sage, Thousand Oaks, California.

Gupta, A.K. and Govindarajan, V. (2000) Knowledge Flows within Multinational Corporations. Strategic Management Journal, 21(4), 473-496.

Hajro, A. (2009) Contextual influences on multinational teams: empirical evidence from an Austrian company. European Journal of International Management, 3 (1), 111-129.

Harzing, A. and Feely, A.J. (2008) The language barrier and its implications for HQsubsidiary relations. Cross-Cultural Management: An International Journal, 15(1), 49-60.

Johnson, J. P., Lenartowicz, T. and Apud, S. (2006) Cross-cultural competence in 
international business: toward a definition and a model. Journal of International Business Studies, 37(4), 525-543.

Joshi, A., and Lazarova, M. (2005) Do Global teams need global leaders? Identifying leadership competences in multinational teams. In Shapiro, D. L., Managing Multinational Teams: Global Perspectives. Elsevier, Amsterdam.

Kirkman, B.L., Rosen, B., Tesluk, P.E., and Gibson, C.B. (2004) The impact of team empowerment on virtual team performance: The moderating role of face-to-face interaction. Academy of Management Journal, 47(5), 175-92.

Matveev, A. V., and Nelson, P. E. (2004) Cross cultural communication competence and multicultural team performance: Perceptions of Americans and Russian Managers. International Journal of Cross Cultural Management, 4(2), 253-270.

Maznevski, M., and DiStefano, J. (2000) Global leaders are team players: Developing global leaders through membership on global teams. Human Resource Management, 39(3), 195-208.

Mayring P. (2000) Qualitative Content Analysis. Forum: Qualitative Social Research. 1(2), 110.

Nonaka, I. and Takeuchi, H. (1995) The knowledge creating company: How Japanese companies create the dynamics of innovation. Oxford University Press, New York.

Numic, A. (2008) Multinational Teams in European and American Companies. Peter Lang Publishing Group, Frankfurt.

O'Reilly C.A., and Chatman J. (1996) Culture as social control: corporations, cults, and commitment. In Staw B.M. and Cummings L.L. (Eds.). Research in Organizational Behaviour, 18, 157-200. Greenwich, CT: JAI Press.

Schweiger, D. M., Atamer, T. and Calori, R. (2003) Transnational project teams and networks: making the multinational organization more effective. Journal of World Business, 38(2), 127-140.

Schwer, S. (2004) Salsa Cultures. Unpublished Master Thesis at the Vienna University of Economics and Business Administration. 
Shapiro, D.L., Furst, S., Spreitzer, G. and Von Glinow M. (2002) Transnational teams in the electronic age: Are team identity and high performance at risk? Journal of Organisational Behaviour, 23(4), 455-67.

Watson, W.E., Johnson, L., and Merritt, D. (1998) Team orientation, self-orientation and diversity in task groups: their connection to team performance over time. Group and Organizational Management, 23(2), 161-189.

Watson, W.E., Kumar, K., and Michaelsen, L.K. (1993) Cultural diversity's impact on interaction process and performance: Comparing homogeneous and diverse task groups, Academy of Management, 36 (3), 590-602.

Witzel, Andreas (2000) The Problem Centred Interview. Forum Qualitative Social Research, 1(1).

Zaccaro, S. J., Rittman, A. L. and Marks, M. A. (2001) Team Leadership. The Leadership Quarterly, 12(4), 451-483.

Zellmer-Bruhn, M. and Gibson, C. (2006) Multinational Organization Context: Implications for Team Learning and Performance. Academy of Management Journal, 49(3), 501-518. 
Table 1: Information on interviewees

\begin{tabular}{|c|c|c|c|c|c|}
\hline Company & Interviees & $\begin{array}{l}\text { Countries } \\
\text { represented }\end{array}$ & Function & Gender & $\begin{array}{l}\text { Educational } \\
\text { Background }\end{array}$ \\
\hline $\begin{array}{l}\text { German } \\
\text { Chemicals } \\
\text { (GC) }\end{array}$ & 15 & $\begin{array}{l}\text { Austria: } 9 \\
\text { Polen: } 2 \\
\text { Ukraine: } 2 \\
\text { Bosnia: } 1 \\
\text { Hungary: } 1\end{array}$ & $\begin{array}{l}\text { Team leaders: } 8 \\
\text { Team members: } \\
7\end{array}$ & $\begin{array}{l}\text { Female: } 8 \\
\text { Male: } 7\end{array}$ & $\begin{array}{l}\text { Master: } 14 \\
\text { Bachelor: } 1\end{array}$ \\
\hline $\begin{array}{l}\text { Austrian } \\
\text { Electronics } \\
\text { (AE) }\end{array}$ & 12 & $\begin{array}{l}\text { Austria: } 6 \\
\text { Spain: } 1 \\
\text { Slovakia: } 1 \\
\text { USA: } 1 \\
\text { South Africa: } 1 \\
\text { Bosnia: } 1 \\
\text { Rumania: } 1\end{array}$ & $\begin{array}{l}\text { Team leaders: } 5 \\
\text { Team members: } \\
7\end{array}$ & $\begin{array}{l}\text { Female: } 3 \\
\text { Male: } 9\end{array}$ & $\begin{array}{l}\text { Master: } 9 \\
\text { Bachelor: } 3\end{array}$ \\
\hline $\begin{array}{l}\text { American } \\
\text { Consumer } \\
\text { Goods } \\
\text { (ACG) }\end{array}$ & 15 & $\begin{array}{l}\text { USA: } 9 \\
\text { India: } 6\end{array}$ & $\begin{array}{l}\text { Team leaders: } 7 \\
\text { Team members: } \\
8\end{array}$ & $\begin{array}{l}\text { Female: } 4 \\
\text { Male: } 11\end{array}$ & $\begin{array}{l}\text { Master: } 3 \\
\text { Bachelor: } 12\end{array}$ \\
\hline $\begin{array}{l}\text { German } \\
\text { Electrical } \\
\text { Engineering } \\
\text { (GEE) }\end{array}$ & 18 & $\begin{array}{l}\text { Austria: } 17 \\
\text { Burma: } 1\end{array}$ & $\begin{array}{l}\text { Team leaders: } \\
12 \\
\text { Team members: } \\
6\end{array}$ & $\begin{array}{l}\text { Female: } 2 \\
\text { Male: } 16\end{array}$ & $\begin{array}{l}\text { Master: } 15 \\
\text { Bachelor: } 3\end{array}$ \\
\hline $\begin{array}{l}\text { Finish } \\
\text { Engineering } \\
\text { Services } \\
(\text { FES) }\end{array}$ & 19 & Austria: 10 & $\begin{array}{l}\text { Team leaders: } 6 \\
\text { Team members: } \\
6\end{array}$ & $\begin{array}{l}\text { Female: } 1 \\
\text { Male: } 9\end{array}$ & $\begin{array}{l}\text { Master: } 7 \\
\text { Bachelor: } 3\end{array}$ \\
\hline Total & 70 & $\begin{array}{l}\text { Austria: } 42 \\
\text { USA: } 10 \\
\text { India: } 6 \\
\text { Polen: } 2 \\
\text { Ukraina: } 2 \\
\text { Bosnia: } 2 \\
\text { Hungary: } 1 \\
\text { Spain: } 1 \\
\text { Slovakia: } 1 \\
\text { South Africa: } 1 \\
\text { Rumania: } 1 \\
\text { Burma: } 1\end{array}$ & $\begin{array}{l}\text { Team leaders: } \\
38 \\
\text { Team members: } \\
32\end{array}$ & $\begin{array}{l}\text { Female: } \\
18 \\
\text { Male: } 52\end{array}$ & $\begin{array}{l}\text { Master: } 48 \\
\text { Bachelor: } 22\end{array}$ \\
\hline
\end{tabular}


Table 2: Team leader characteristics and functions

\begin{tabular}{lcc}
\hline Team leader competences & $\begin{array}{c}\text { Percentage of } \\
\text { interviews* }\end{array}$ & $\begin{array}{c}\text { Number of } \\
\text { quotations }\end{array}$ \\
\hline Knowledge management and transfer & $47 \%$ & 77 \\
Cross-cultural awareness & $20 \%$ & 30 \\
Motivation & $20 \%$ & 25 \\
Social competence & $20 \%$ & 23 \\
Goal setting & $16 \%$ & 13 \\
Decision-making & $14 \%$ & 12 \\
Selection of team members & $11 \%$ & 18 \\
Delegation of tasks & $11 \%$ & 15 \\
Constructive monitoring & $11 \%$ & 13 \\
Knowledge of foreign languages & $11 \%$ & 10 \\
Work experience & $11 \%$ & 9 \\
Coordination & $10 \%$ & 14 \\
Transfer of HQ's organisational culture & $10 \%$ & 7 \\
Coaching & $7 \%$ & 10 \\
Conflict management & $7 \%$ & 8 \\
Strengths and weaknesses of MNT & $7 \%$ & 6 \\
members & & \\
Creation of collective team identification & $6 \%$ & 7 \\
Ability to show humility & $6 \%$ & 5 \\
Self-awareness & $3 \%$ & 4 \\
Virtual team leadership & $3 \%$ & 2 \\
\hline
\end{tabular}

$* 100 \%=70$ interviews 